\title{
Model-Free Neural Network-Based Predictive Control for Robust Operation of Power Converters
}

\author{
Sanaz Sabzevari ${ }^{1}\left(\mathbb{D}\right.$, Rasool Heydari $^{2}$, Maryam Mohiti $^{3}$, Mehdi Savaghebi ${ }^{4, *}$ and Jose Rodriguez ${ }^{5}(\mathbb{D}$ \\ 1 Department of Electrical and Computer Engineering, Semnan University, Semnan 35131-19111, Iran; \\ s_sabzevari@mut.ac.ir \\ 2 Energy Technology Department, Aalborg University of Denmark, 9220 Aalborg, Denmark; rah@et.aau.dk \\ 3 Department of Electrical Engineering, University of Yazd, Yazd 89158-18411, Iran; m.mohiti@ut.ac.ir \\ 4 Department of Mechanical and Electrical Engineering, University of Southern Denmark, \\ 5230 Odense, Denmark \\ 5 Department of Engineering Science, Universidad Andres Bello, 7500971 Santiago, Chile; \\ jose.rodriguez@unab.cl \\ * Correspondence: mesa@sdu.dk
}

Citation: Sabzevari, S.; Heydari, R.; Mohiti, M.; Savaghebi, M.; Rodriguez, J. Model-Free Neural Network-Based Predictive Control for Robust Operation of Power Converters. Energies 2021, 14, 2325. https:// doi.org/10.3390/en14082325

Academic Editor: Teuvo Suntio

Received: 7 March 2021

Accepted: 17 April 2021

Published: 20 April 2021

Publisher's Note: MDPI stays neutral with regard to jurisdictional claims in published maps and institutional affiliations.

Copyright: (c) 2021 by the authors. Licensee MDPI, Basel, Switzerland. This article is an open access article distributed under the terms and conditions of the Creative Commons Attribution (CC BY) license (https:// creativecommons.org/licenses/by/ $4.0 /)$.

\begin{abstract}
An accurate definition of a system model significantly affects the performance of modelbased control strategies, for example, model predictive control (MPC). In this paper, a model-free predictive control strategy is presented to mitigate all ramifications of the model's uncertainties and parameter mismatch between the plant and controller for the control of power electronic converters in applications such as microgrids. A specific recurrent neural network structure called state-space neural network (ssNN) is proposed as a model-free current predictive control for a three-phase power converter. In this approach, NN weights are updated through particle swarm optimization (PSO) for faster convergence. After the training process, the proposed ssNN-PSO combined with the predictive controller using a performance criterion overcomes parameter variations in the physical system. A comparison has been carried out between the conventional MPC and the proposed model-free predictive control in different scenarios. The simulation results of the proposed control scheme exhibit more robustness compared to the conventional finite-control-set MPC.
\end{abstract}

Keywords: model-free predictive control; model predictive control (MPC); power converter; state-space neural network with particle swarm optimization (ssNN-PSO); identification; robust performance

\section{Introduction}

\subsection{Motivation and Aim}

In recent years, the global share of converter interfaced-renewable energy sources (RESs) has grown rapidly, for example the share of wind farms and photovoltaic (PV) exceeded 27\% by the end of 2019 [1]. Moreover, the European Union has set a binding target of at least $32 \%$ for electrical generation from RESs by 2030 , which leads to around a $55 \%$ net greenhouse gas emissions reduction, and Sweden has set an ambitious target of $100 \%$ renewable energy production by 2040, and net-zero emissions by 2045 [2]. However, with the increasing penetration of converter interfaced-RESs, the inertia of the power grid reduces and poses major stability issues to the power system. To overcome these stability issues, converter interfaced-RESs should be equipped with a robust, fast, and reliable control strategy. Power converters are the backbone of modern power systems and microgrids. Conventional multi-loop structures with linear controllers, for example, proportional integrator (PI), proportional integral derivative (PID), proportional derivative (PD), and proportional resonant (PR) are widely used to control the output of power converters interfaced-RESs. To avoid undesired interactions in multi-control loops, the inner loops should be designed with a higher bandwidth compared to the outer one. Consequently, the outer loops have slow dynamics, and hence, the multi-loop control strategy 
has an inherent slow dynamic response. Furthermore, the conventional linear controllers mostly rely on the system parameters. Therefore, changes in the system structure and uncertainty of RESs can degrade the controller performances and may lead to system instability. This paper aims to present a model-free and robust control strategy for converter interfaced-RESs. The objective of the control method is to enhance its robustness to system parameter mismatch and uncertainty of RESs generation by presenting a state-space neural network-based predictive control method.

\subsection{Literature Review}

Recently advanced control strategies are presented in the literature to address the slow performance of linear multi-loop control strategies while demonstrating fast and accurate dynamic behavior. Model predictive control is a promising alternative to conventional multi-loop controllers, which has the advantages of a fast response [3-7], possibility of implementing multivariable control, and incorporating non-linearity in the model and constraints [8]. Simulation and experimental results in $[9,10]$ show that the MPC-based methods represent higher performance compared to the conventional linear controllers. MPC methods applied to converters can be classified into two categories: Continuouscontrol-set MPC (CCS-MPC) and finite-control-set MPC (FCS-MPC) [11]. In CCS-MPC continuous signals are generated for the PWM regulator, while FCS-MPC is based on the discrete nature of the converter. In FCS-MPC, the optimal control input among a finite set of control actions, the viable combination of the switching states, are chosen [12]. Due to the advantages of not requiring a modulation strategy and simplicity, FCS-MPC is extensively adopted in many applications, such as control of power electronic converters [13-15].

Explicit MPCs (E-MPCs) were introduced to lessen the online computation burden of MPCs. In E-MPCs, the optimization problem of the MPC is solved offline, and in real-time operation the controller only searches between the offline solutions [16]. In [17-19], similar to E-MPC a deep neural network (NN) is trained offline to learn the optimal control policy of the MPC, and in real-time the trained NN is executed rapidly on embedded hardware. In [20], MPC is employed to extract the data for the off-line training phase and the trained $\mathrm{NN}$ controls the output voltage of the converter without the need of the MPC. Generally and as the above work, the prediction horizon of FCS-MPC is kept constant and is chosen by the trade-off between the performance and the computation burden. Authors of [21] present an adaptive prediction horizon for the FCS-MPC of power converters in which a NN is trained to optimize the optimal prediction horizon of the FCS-MPC. In [22], an artificial neural network-based approach is applied to optimize the weighting factors of the MPC controller. The system is simulated numerous times and voltage total harmonic distortion (THD) and average switching frequency are extracted for every combination of the weighting factors. The simulated data is then used to train the NN. The authors of [23] have similarly tuned the weighting factors of the FCS-MPC, applied to a grid-tied multilevel inverter, by a feed-forward NN.

These papers have made a great effort in enhancing MPC controller's performance from different aspects. However, they are still based on the accurate definition of the system model. Therefore, any uncertainty in the model definition or parameter change directly affects system performance. Thus, one critical issue for predictive control (PC) is how to create robustness against parameter mismatch and minimize the requirement for knowledge of the physical system so that the process outputs have less distortion and better prediction. To this end, numerous approaches have been presented recently, like model-free predictive controllers. In this regard, authors of [24] similar to $[25,26]$ present a model-free PC where the motor current variations, due to applying each eight base inverter voltage vectors, are measured and dynamically stored in a look-up table. Based on these measurements, the current variations are predicted. This approach relaxes the dependency of the PC on the system model. However, the updated frequency of the measurements has a dramatic effect on the performance of the method. In [27], a model-free PC is presented in which the motor current slopes are expressed by the current variations of the previous 
samples and their associated voltage vectors. Based on the predicted current slopes, the optimal voltage vectors are selected directly. The main drawbacks of these studies are the limitations of the current measurements despite relative improvements $[27,28]$. The parameters of an auto-regressive with exogenous input (ARX) model are identified by the recursive least squares algorithm used for the current control of a two-level, three-phase voltage source inverter in $[28,29]$. The dependency to the initial set value and computational burden are the major disadvantages of this approach, notwithstanding its robust feature concerning filter model mismatch.

To circumvent these issues, data-based strategies based on artificial intelligence can be adopted to estimate the model of the system. A neural network structure can reap the benefits of mimicking the plant's behavior without considering any mathematical model. However, the state-space matrix of the system is required to reproduce dynamical behaviors through feedback connections for the identification of the predictive control model. Consequently, a state-space neural network (ssNN) can be applied to identify dynamical systems as one of the recurrent neural network approaches [30].

To mitigate the time-consuming trial-and-error approach, the learning process for adjusting the NN weights can be achieved by an optimization algorithm [31,32]. Intelligible neural weights are adapted and learned along with state-space representation. Various state-of-art iterative techniques have been employed for solving optimization problems acting such as the Lagrange multiplier method [33], mathematical programming methods [34], and genetic algorithm (GA) [35]. Among these techniques, particle swarm optimization (PSO) mitigates the related issues such as heavy computational burden, dependency on the initial guess setting, and detailed knowledge of the controlled system [36,37].

\subsection{Contribution}

The major contribution of this paper is to present a model-free predictive control for the robust operation of power converters. In the proposed method, a state-space neural network (ssNN) is incorporated with predictive control to enhance the robustness in a databased learning algorithm as a model-free approach. In the proposed approach, an ssNN is applied to identify the state space matrix of the system for the PC. Input/output data are derived from the measurements of the controlled system and, consequently, the dynamical behavior of the system through feedback connections can be modeled and updated. This not only enhances the dynamic behavior of the proposed method but also makes it robust to system parameter variations and RES's uncertainties. Furthermore, PSO is applied to optimize the weight of the SSNN and reduce the computational burden of the proposed approach. To evaluate the proposed performance, it is compared to the conventional MPC under various filter model mismatches.

The paper is organized as follows. Conventional MPC is introduced in Section 2. Section 3 presents the proposed state-space neural network structure optimized by PSO with a predictive controller. It also mentions the learning process of the proposed strategy. Simulation results are provided in Section 4. It also describes the impact of parameter mismatch and uncertainty on the inductor current, while conclusions are stated in Section 5.

\section{Conventional Model Predictive Control}

In general, the classical FCS-MPC strategies take merits of the defined number of switching states generated by power converters. Then, the controller can optimally select the proper state in terms of given control requirements. This approach is succinctly indicated in Figure 1. 


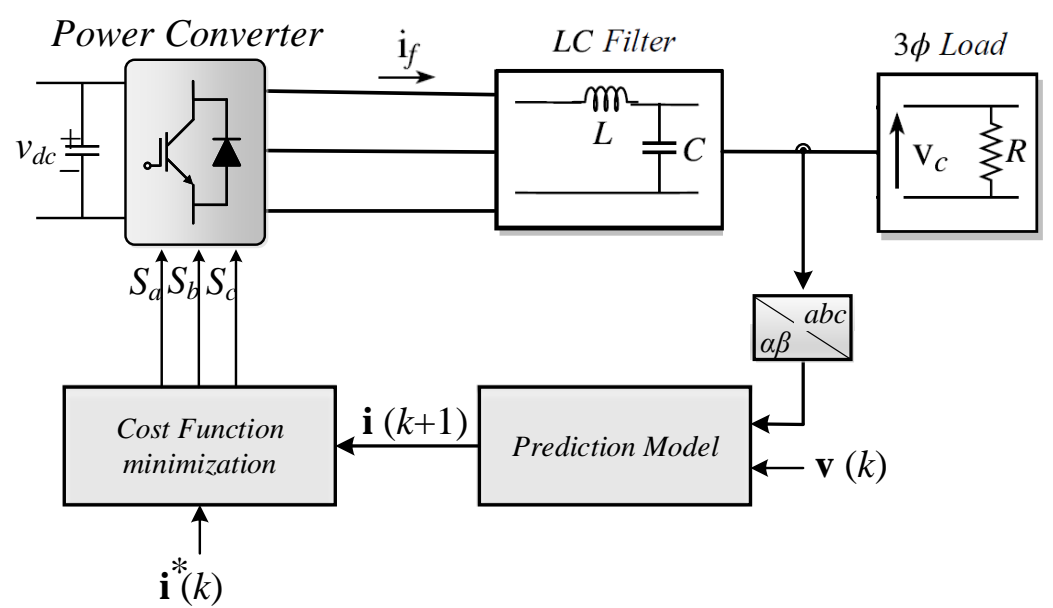

Figure 1. Conventional model predictive control strategy for an inverter.

Considering a generic two-level, three-phase power inverter, there are six switches that generate the output. Thus, eight switching states can be determined by three main gating signals, i.e., $S_{a}, S_{b}$, and $S_{c}$ as defined in [38], and expressed in vectorial form as follows [15]:

$$
\mathbf{S}=\frac{2}{3}\left(S_{a}+\mathbf{a} S_{b}+\mathbf{a}^{2} S_{c}\right)
$$

where $\mathbf{a}=e^{j \pi / 3}$.

Therefore, the converter output voltage state vector can be defined by:

$$
\mathbf{v}=\frac{2}{3}\left(v_{a N}+\mathbf{a} v_{b N}+\mathbf{a}^{2} v_{c N}\right)
$$

The controller should be able to apply the proper switching state to provide an appropriate output voltage.

To achieve a precise control strategy, a discrete model of the system (load or filter) is utilized to accurately predict the future values of the output current at the sampling instant $k+1$, for all eight voltage vectors $v(k)$ generated by the power converter. Considering an RL load model, the prediction can be carried out by using Euler's method for discretization in the $\alpha-\beta$ reference frame representation [39]:

$$
\left[\begin{array}{l}
i_{\alpha}^{p}(k) \\
i_{\beta}^{p}(k)
\end{array}\right]=\left(1-\frac{R T_{s}}{L}\right)\left[\begin{array}{l}
i_{\alpha}(k-1) \\
i_{\beta}(k-1)
\end{array}\right]+\frac{T_{s}}{L}\left[\begin{array}{l}
v_{\alpha}(k-1) \\
v_{\beta}(k-1)
\end{array}\right]
$$

here the superscript $p$ stands for the predicted variables sampling instant $k+1$, and $T_{S}$ is the sampling step time. Note that the model parameters are the inductance $L$ and resistance $R$ load, which has no fixed value.

At the next step, a cost function (CF) should be defined to optimize the switching states. Therefore, the main objective here is to track the current reference $i_{\alpha}^{*}$ and $i_{\beta}^{*}$ as follows:

$$
C F=\left|i_{\alpha}^{*}(k+1)-i_{\alpha}^{p}(k+1)\right|^{2}+\left|i_{\beta}^{*}(k+1)-i_{\beta}^{p}(k+1)\right|^{2} .
$$

The controller enforces the output current to follows the predefined reference current by means of (4). This strategy eliminates the requirement for pulse-width modulation (PWM), as well as multi-loop controllers. Consequently, it can react very fast and accurately follow the reference. However, as mentioned before, the main drawback of the classical FCS-MPC is its dependency on the system model accuracy in the prediction and cost function (3). 
Therefore, any small changes in the model parameters or model mismatch and uncertainties have a significant effect on the controller performances. To address the aforementioned drawbacks of the classical FCS-MPC, a model-free predictive control based on the neural network is proposed in the following section.

\section{Proposed ssNN-PSO-Based PC}

This section provides the state-space neural network architecture using data (extracted by implementation or simulation) to be employed in voltage source inverters with predictive control. The optimum weights in ssNN are learned through particle swarm intelligence. The schematic of the proposed ssNN-PSO is illustrated in Figure 2. Consequently, a novel approach is elaborated to make it more concrete.

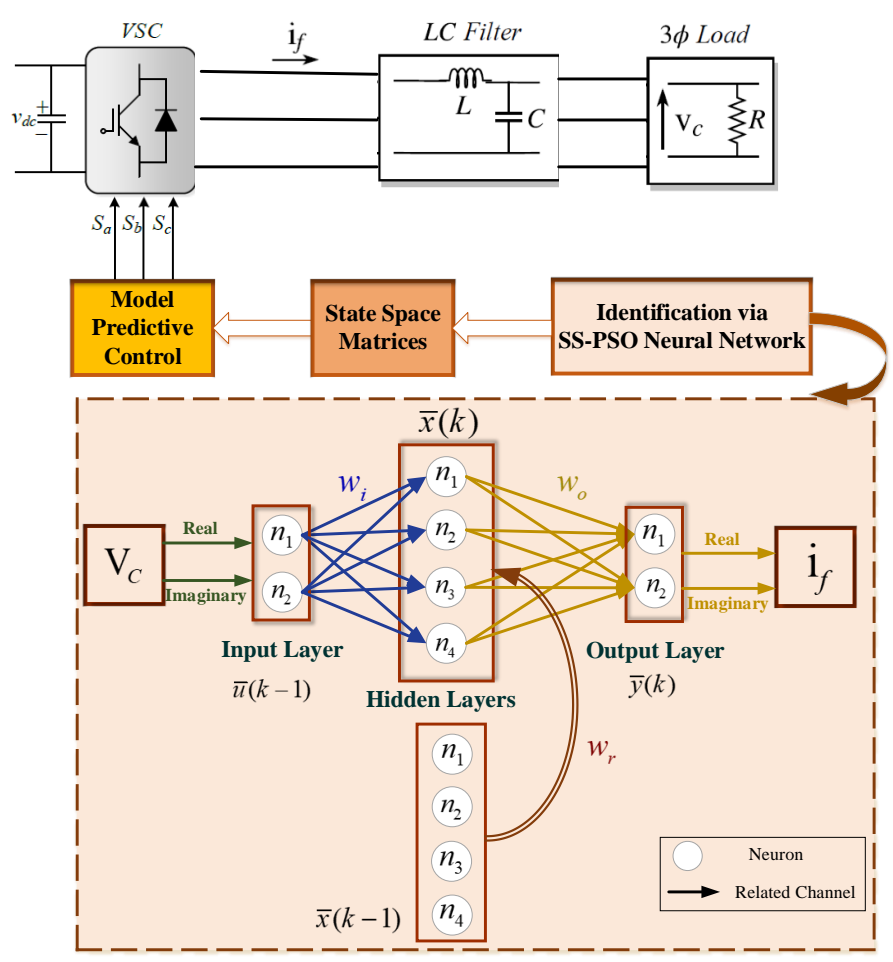

Figure 2. Proposed architecture.

\subsection{Identification Methodology}

In the model predictive control approach, a linear state-space representation of a dynamic system is required. However, model parameter values in a three-phase power converter are ambiguous in a real case. Hence, the identification method, which entails robustness with respect to variations of unknown values, is a requisite in this situation. To delineate this method, the scheme is illustrated in Figure 3.

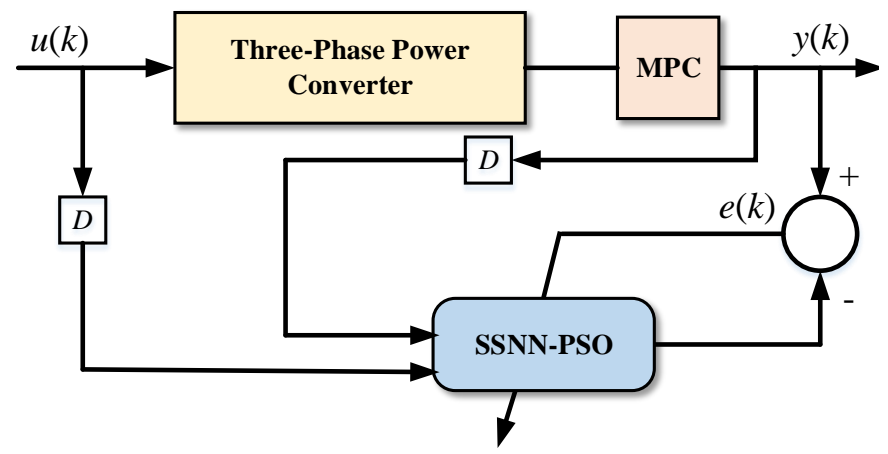

Figure 3. Identification scheme. 
In Figure 3, D stands for discretization as sampling data. The inputs of ssNN are the control signal and output process to achieve the system dynamics.

The crucial objective of the identification is to duly tackle the sources and loads' uncertainty while obtaining an accurate dynamical model.

\subsection{Description of Learning Algorithm}

After the data extraction from the simulation model, the training phase is carried out. However, finding the optimum weights of the NN may be challenging when training the data set. In other words, the output of training yields the state-space matrices based on (5). MPC performance is dependent on the dynamical model. Hence, an optimization algorithm is adopted to observe ssNN-weights:

$$
\left\{\begin{array}{l}
\bar{x}(k)=w_{r} \bar{x}(k-1)+w_{i} \bar{u}(k-1) \\
\bar{y}(k)=w_{o} \bar{x}(k)
\end{array}\right.
$$

where $w_{r}, w_{i}$, and $w_{0}$ are identical to the weights in Figure 2.

The particle swarm optimization is a population-based algorithm with a swarm of random particles. Each particle (i) moves in a problem space with a velocity updated at each time step $\left(V_{i}=\left(v_{i 1}, \ldots, v_{i j}, \ldots v_{i k}\right)\right)$, where $k$ is the dimensional problem space. The current location of the $i$ th particle is presented by $\left(X_{i}=\left(x_{i 1}, \ldots, x_{i j}, \ldots x_{i k}\right)\right)$. The best location of particle $i$, until the current search and globally among all populations, are indexed as $\left(P_{i}=\left(p_{i 1}, \ldots, p_{i j}, \ldots p_{i k}\right)\right)$ and $P_{g}$, respectively. The particle's locations and velocities are adjusted by $P_{i}$ and $P_{g}$ (gbest) as follows:

$$
\begin{aligned}
& v_{i j}^{\text {new }}=\omega v_{i j}+c_{1} r_{1}\left(p_{i j}-x_{i j}\right)+c_{2} r_{2}\left(p_{g j}-x_{i j}\right), \\
& x_{i j}^{\text {new }}=x_{i j}+v_{i j}^{\text {new }}
\end{aligned}
$$

where $c_{1}$ and $c_{2}$ are acceleration constants. In addition, $r_{1}$ and $r_{2}$ are uniform random numbers. $\omega$ is the time-varying weight factor determining the influence of the previous velocity values on the updated particle velocity and can be considered as (7).

$$
\omega=\omega_{\max }-\frac{t}{t_{\max }}\left(\omega_{\max }-\omega_{\min }\right)
$$

where max, min subscripts imply maximum and minimum values of the weight factor, respectively, $t$ is the number of iteration, and $t_{\max }$ is the maximum number of iteration selected to achieve the optimal solution with suitable convergence for training data.

Further information regarding the PSO procedure appears as a prevalent optimization algorithm mentioned in various articles like [36].

PSO is utilized to learn ssNN in order to match appropriately with the detailed simulation data. It is worth mentioning that the trained network is opted to avoid the overfitting and underfitting occurrence. The mean square error (MSE) is calculated in (8) for a given training set as a performance index.

$$
M S E=\sum_{k=1}^{N}\|e(k)\|^{2}
$$

where $N$ is the number of training data.

PSO adjusts the weights to minimize MSE between the estimated and desired values.

The ssNN network comprises an input layer, two hidden layers with the time delay recurrent channel, and an output layer in a feed-forward connection pattern illustrated in Figure 2. To this end, the activation function employed in this structure is purelin [40]. A performance evaluation of the training phase of ssNN-PSO should be conducted prior to applying the optimum weights. Consequently, the MSE of the proposed network obtained for the voltage source converter is depicted in Figure 4. In particular, 1000 samples are utilized as the training data. 


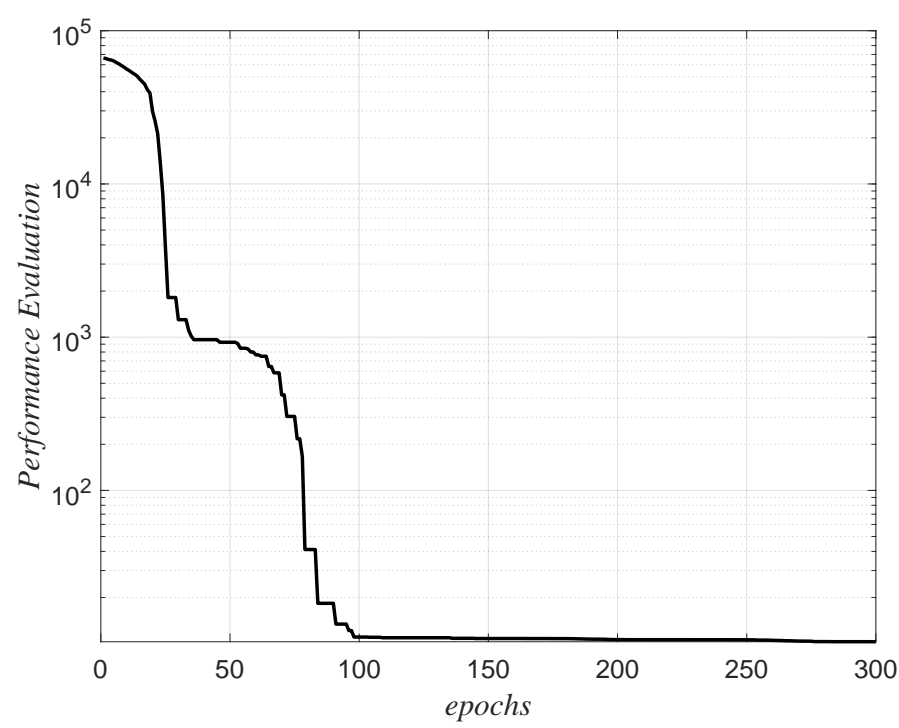

Figure 4. The MSE of the training phase.

\section{Simulation Results and Comparison}

In this paper, the proposed ssNN-PSO is applied to system identification of Figure 2 (a three-phase voltage source inverter connected to a load) to investigate its robustness performance. That is, it is learned to substitute the mathematical model and circumvent the uncertainty consequences along with MPC. To verify its effectiveness, simulations have been carried out based on the model parameters presented in Table 1.

Table 1. System Parameters in Simulation.

\begin{tabular}{cc}
\hline Parameter & Value \\
\hline Peak AC voltage,$V_{\max }$ & $200[\mathrm{~V}]$ \\
Sampling rate, $f_{s}$ & $40[\mathrm{kHz}]$ \\
System frequency, $f_{\text {sys }}$ & $50[\mathrm{~Hz}]$ \\
Load parameter (resistance), $R_{L}$ & $10[\omega]$ \\
Load parameter (inductance), $L_{L}$ & $10[\mathrm{mH}]$ \\
Load parameter (nominal current), $i_{r}$ & $10[\mathrm{~A}]$ \\
Maximum of weight factor, $\omega_{\max }$ & 0.9 \\
Minimum of weight factor, $\omega_{\min }$ & 0.4 \\
Acceleration coefficients, $c_{1}, c_{2}$ & 2 \\
\hline
\end{tabular}

The proposed network's training data set consists of 1000 sampling data from input and output measurements of the controlled system extracted from Simulink. Moreover, the data is discretized based on the sample time of $T_{s}$. Furthermore, the number of PSO populations is 50 , and the rest of its parameters have opted the same as the corresponding literature (for example, [31]). The comparison has been performed for MPC with a known mathematical model and the identification block.

After the learning process, the optimum weights, which are the best results of ssNN, are obtained. Therefore, the plant in (5) is identified after 2000 iterations as follows: 


$$
\begin{aligned}
& \bar{x}_{\alpha}(k)=\underbrace{\left[\begin{array}{cccc}
0.9964 & 0.0017 & -0.0064 & -0.0588 \\
-0.0255 & -0.0377 & -0.1932 & 0.0307 \\
-0.2486 & 1.4425 & 0.2245 & -0.1283 \\
-0.0748 & -0.0813 & 0.5713 & -0.7654
\end{array}\right]}_{w_{r}} \cdot \bar{x}_{\alpha}(k-1)+ \\
& \underbrace{\left[\begin{array}{cc}
6.89 \times 10^{-4} & 6.33 \times 10^{-4} \\
6.007 \times 10^{-4} & -8.66 \times 10^{-5} \\
8.47 \times 10^{-4} & -3.38 \times 10^{-6} \\
0
\end{array}\right]}_{w_{i}} \cdot \bar{u}_{\alpha}(k-1), \\
& \bar{y}_{\alpha}(k)=\underbrace{\left[\begin{array}{llll}
1 & 0 & 0 & 0
\end{array}\right]}_{w_{0}} \cdot \bar{x}_{\alpha}(k) . \\
& \bar{x}_{\beta}(k)=\underbrace{\left[\begin{array}{cccc}
0.9863 & 0.0534 & -0.0524 & 0.2686 \\
-0.1809 & 0.0964 & -0.5691 & -0.0397 \\
-0.1561 & -0.2017 & 0.2320 & -0.0355 \\
-0.1848 & -0.1855 & -0.2263 & -0.4189
\end{array}\right]}_{w_{r}} \cdot \bar{x}_{\beta}(k-1)+ \\
& \underbrace{\left[\begin{array}{cc}
-7.602 \times 10^{-5} & 8.503 \times 10^{-4} \\
-4.84 \times 10^{-5} & 4.83 \times 10^{-4} \\
6.88 \times 10^{-4} & 5.21 \times 10^{-4} \\
0
\end{array}\right]} \cdot \bar{u}_{\beta}(k-1) \\
& \bar{y}_{\beta}(k)=\underbrace{\left[\begin{array}{llll}
w_{i} \\
1 & 0 & 0 & 0
\end{array}\right]}_{w_{0}} \bar{x}_{\beta}(k) .
\end{aligned}
$$

State variables and input/output measurements are denoted in the complex $\alpha-\beta$ format, and subscripts $\alpha$ and $\beta$ stand for real and imaginary data, respectively.

The behavior of the proposed identification structure for a specified resistive load $(R)$ and inductor of the filter $(L)$ using predictive control is shown in Figure 5, while MPC's behavior without identification for the same conditions is depicted in Figure 6. It is worth noting to mention that similar parameters and sampling time (simulation step) are applied for both methods to ensure a fair comparison.
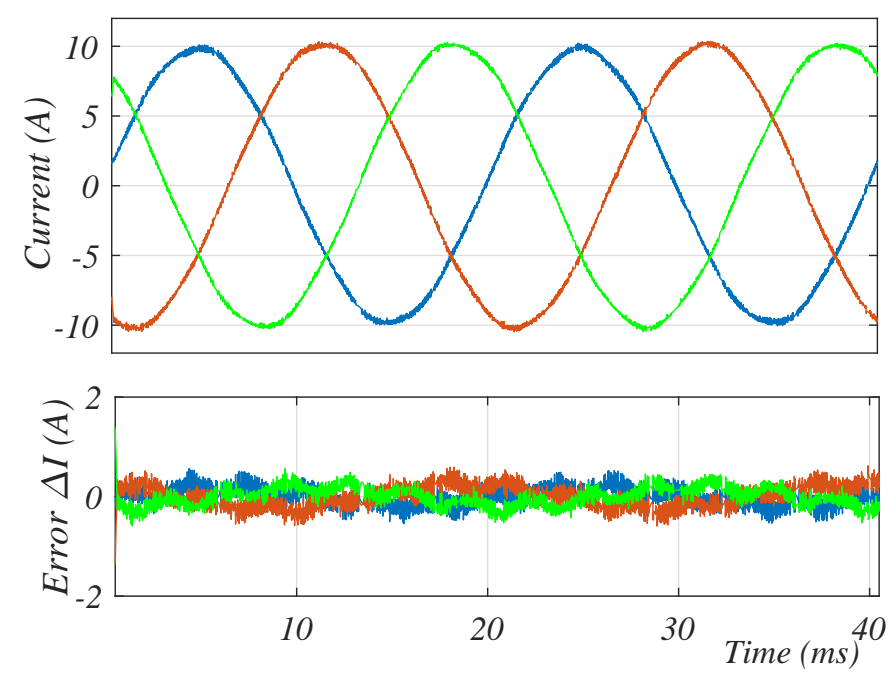

Figure 5. Simulation results of ssNN-PSO-based predictive control: Output current for specified resistive load and filter inductance. (Red line: $i_{a}$, Green line: $i_{b}$, Blue line: $i_{c}$ ). 

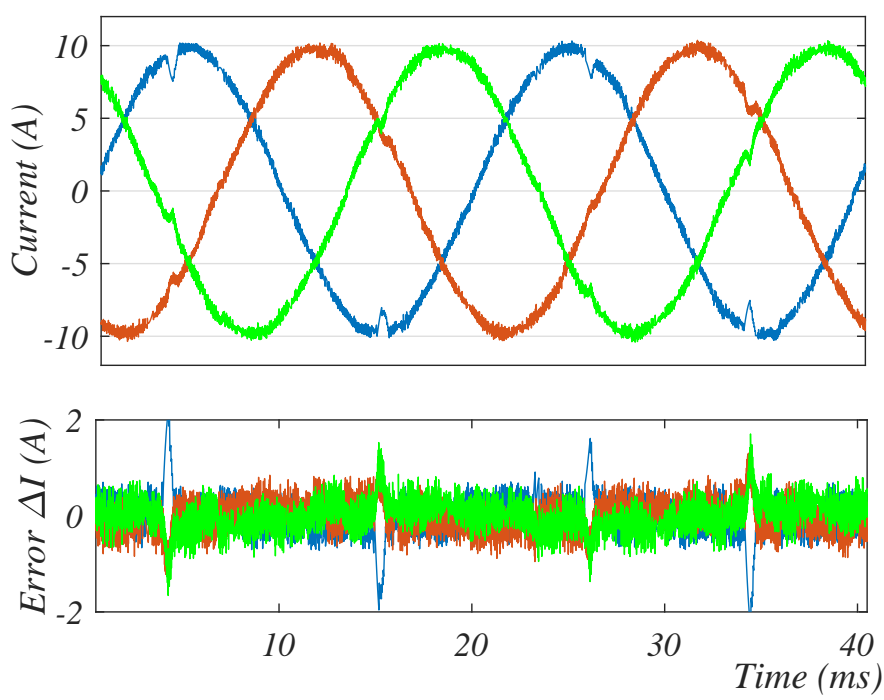

Figure 6. Simulation results of MPC without identification: Output current for specified resistive load and filter inductance.

It can be seen that the inductor current $\left(i_{f}\right.$ in Figure 2$)$ in both figures is sinusoidal with low distortion, particularly for the ssNN-PSO-based PC, which has an MSE of 0.042 compared to 0.137 for MPC without identification.

To turn out the feasibility of the proposed approach under realistic operating conditions, the resistive load is doubled $(R \times 2)$, and the filter inductance is halved $\left(\frac{L}{2}\right)$.

Figure 7 demonstrates the conventional MPC degradation performance through uncertainty and the parametric mismatch. In contrast, ssNN-PSO-based predictive control performs satisfactorily under parameter change of the physical load after activation at $t=60 \mathrm{~ms}$.

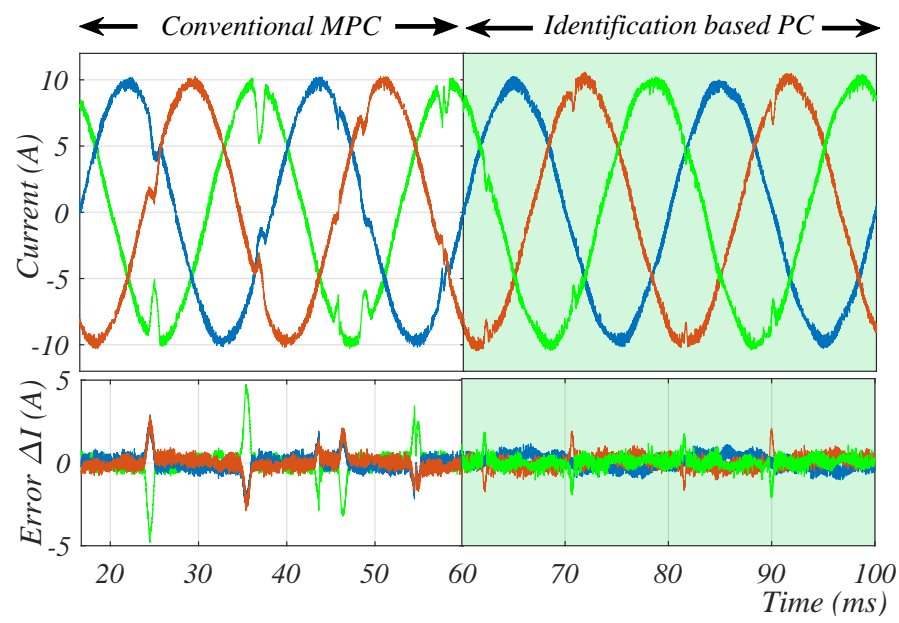

Figure 7. Impact of parameter mismatch on steady state output current of VSC: Double specified resistive load $(R \times 2)$ and one half of filter inductance $\left(\frac{L}{2}\right)$.

For further investigation of the robustness, five scenarios are considered as listed in Table 2. As can be observed in Table 2, the inductor current generated by the identificationbased approach totally outperforms that obtained using conventional MPC. The increased error due to the second variation is trivial in comparison to the rest mismatches in Table 2. 
Table 2. Comparison parameter changes between model-free and model-based predictive control.

\begin{tabular}{ccc}
\hline Mismatch Parameters & MSE (A) (Conventional MPC) & MSE (A) (ssNN-PSO Based PC) \\
\hline$(L \times 0.5, R \times 1.5)$ & 0.252 & 0.100 \\
$(L \times 1.5, R \times 0.5)$ & 0.006 & 0.015 \\
$(L \times 0.6, R \times 2)$ & 0.281 & 0.094 \\
$(L \times 0.5, R \times 2)$ & 0.822 & 0.122 \\
$(L \times 0.3, R \times 2)$ & 2.096 & 0.289 \\
\hline
\end{tabular}

It is noteworthy that the ssNN-PSO identification approach with predictive control is more robust than conventional MPC in a fair comparison condition.

\section{Conclusions}

A model-free strategy using a state-space NN to identify a three-phase power converter's dynamic model was successfully investigated and developed under parameter mismatch conditions. The inductance's output current was controlled by the predictive controller, regardless of the system's mathematical model. To make an appraisal of the proposed strategy, a comparison was carried out between conventional MPC and the proposed model-free approach. As can be expected, inevitably in any model-based process variations of the system model degraded the performance while demonstrating relative robustness in the proposed method. The developed approach had fast convergence due to utilizing PSO for obtaining optimum weights. As in any linear model state-space strategy, nonlinearities in the system inevitably influence the neural network structure's design. Therefore, the possible direction for future applications would be the implementation of the ssNN-PSO-based predictive control for complex systems with a nonlinear model.

Author Contributions: Conceptualization, S.S. and R.H.; methodology, S.S.; software, S.S. and R.H.; validation, S.S., R.H., and M.S.; formal analysis, R.H.; investigation, M.M., M.S. and J.R.; resources, R.H., and M.M.; data curation, S.S. and R.H.; writing-original draft preparation, S.S. and R.H.; writing-review and editing, M.M., S.S., and M.S.; visualization, J.R.; supervision, J.R.; project administration, M.S.. All authors have read and agreed to the published version of the manuscript.

Funding: This research received no external funding.

Institutional Review Board Statement: Not applicable.

Informed Consent Statement: Not applicable.

Data Availability Statement: Not applicable.

Acknowledgments: J. Rodriguez acknowledges the support of ANID through projects FB0008, ACT192013 and 1210208.

Conflicts of Interest: The authors declare no conflict of interest.

\section{References}

1. Christensen, P.; Andersen, G.K.; Seidel, M.; Bolik, S.; Engelken, S.; Knueppel, T.; Krontiris, A.; Wuerflinger, K.; Bülo, T.; Jahn, J.; et al. High Penetration of Power Electronic Interfaced Power Sources (HPoPEIPS)-ENTSO-E Guidance Document for National Implementation for Network Codes on Grid Connection; ENTSO-E Tech. Rep.; 2020; pp. 1-61. Available online: https://strathprints.strath.ac.uk/72581/ (accessed on 19 April 2021).

2. Charlotte Unger Larson 100 Percent Renewable Electricity by 2040; Swedish Wind Energy Association: Stockholm, Sweden, 2019.

3. Dragičević, T. Model Predictive Control of Power Converters for Robust and Fast Operation of AC Microgrids. IEEE Trans. Power Electron. 2017, 33, 6304-6317. [CrossRef]

4. Rodriguez, J.; Pontt, J.; Silva, C.A.; Correa, P.; Lezana, P.; Cortes, P.; Ammann, U. Predictive Current Control of a Voltage Source Inverter. IEEE Trans. Ind. Electron. 2007, 54, 495-503. [CrossRef]

5. Heydari, R.; Gheisarnejad, M.; Khooban, M.H.; Dragicevic, T.; Blaabjerg, F. Robust and Fast Voltage-Source-Converter (VSC) Control for Naval Shipboard Microgrids. IEEE Trans. Power Electron. 2019, 34, 8299-8303. [CrossRef]

6. Heydari, R.; Khayat, Y.; Amiri, A.; Dragicevic, T.; Shafiee, Q.; Popovski, P.; Blaabjerg, F. Robust High-Rate Secondary Control of Microgrids with Mitigation of Communication Impairments. IEEE Trans. Power Electron. 2020, 35, 12486-12496. [CrossRef] 
7. Khayat, Y.; Shafiee, Q.; Heydari, R.; Naderi, M.; Dragičević, T.; Simpson-Porco, J.W.; Dörfler, F.; Fathi, M.; Blaabjerg, F.; Guerrero, J.M.; et al. On the Secondary Control Architectures of AC Microgrids: An Overview. IEEE Trans. Power Electron. 2020, 35, 6482-6500. [CrossRef]

8. Hu, J.; Shan, Y.; Guerrero, J.M.; Ioinovici, A.; Chan, K.W.; Rodriguez, J. Model predictive control of microgrids-An overview. Renew. Sustain. Energy Rev. 2021, 136, 110422. [CrossRef]

9. Heydari, R.; Dragicevic, T.; Blaabjerg, F. High-bandwidth Secondary Voltage and Frequency Control of VSC-based AC Microgrid. IEEE Trans. Power Electrons. 2019, 34, 11320-11331. [CrossRef]

10. Heyderi, R.; Alhasheem, M.; Dragicevic, T.; Blaabjerg, F. Model predictive control approach for distributed hierarchical control of vsc-based microgrids. In Proceedings of the 2018 20th European Conference on Power Electronics and Applications (EPE'18 ECCE Europe), Riga, Latvia, 17-21 September 2018; p. P-1.

11. Vasilakis, A.; Zafeiratou, I.; Lagos, D.T.; Hatziargyriou, N.D. The Evolution of Research in Microgrids Control. IEEE Open Access J. Power Energy 2020, 7, 331-343. [CrossRef]

12. Borreggine, S.; Monopoli, V.G.; Rizzello, G.; Naso, D.; Cupertino, F.; Consoletti, R. A review on model predictive control and its applications in power electronics. In Proceedings of the 2019 AEIT International Conference of Electrical and Electronic Technologies for Automotive (AEIT AUTOMOTIVE), Turin, Italy, 2-4 July 2019; pp. 1-6.

13. Kouro, S.; Cortés, P.; Vargas, R.; Ammann, U.; Rodríguez, J. Model predictive control-A simple and powerful method to control power converters. IEEE Trans. Ind. Electron. 2008, 56, 1826-1838. [CrossRef]

14. Vasquez, J.C.; Guerrero, J.M.; Savaghebi, M.; Eloy-Garcia, J.; Teodorescu, R. Modeling, analysis, and design of stationaryreference-frame droop-controlled parallel three-phase voltage source inverters. IEEE Trans. Ind. Electron. 2013, 60, 1271-1280. [CrossRef]

15. Rodriguez, J.; Kazmierkowski, M.P.; Espinoza, J.R.; Zanchetta, P.; Abu-Rub, H.; Young, H.A.; Rojas, C.A. State of the art of finite control set model predictive control in power electronics. IEEE Trans. Ind. Inform. 2012, 9, 1003-1016. [CrossRef]

16. Chen, J.; Chen, Y.; Tong, L.; Peng, L.; Kang, Y. A Backpropagation Neural Network-Based Explicit Model Predictive Control for DC-DC Converters With High Switching Frequency. IEEE J. Emerg. Sel. Top. Power Electron. 2020, 8, 2124-2142. [CrossRef]

17. Lucia, S.; Navarro, D.; Karg, B.; Sarnago, H.; Lucia, O. Deep learning-based model predictive control for resonant power converters. IEEE Trans. Ind. Inform. 2020, 17, 409-420. [CrossRef]

18. Wang, S.; Dragicevic, T.; Gao, Y.; Teodorescu, R. Neural Network based Model Predictive Controllers for Modular Multilevel Converters. IEEE Trans. Energy Convers. 2020, 1-10. [CrossRef]

19. Sarali, D.S.; Selvi, V.A.I.; Pandiyan, K. An Improved Design for Neural-Network-Based Model Predictive Control of Three-Phase Inverters. In Proceedings of the 2019 IEEE International Conference on Clean Energy and Energy Efficient Electronics Circuit for Sustainable Development (INCCES), Krishnankoil, India, 18-20 December 2019; pp. 1-5.

20. Mohamed, I.S.; Rovetta, S.; Do, T.D.; Dragicević, T.; Diab, A.A.Z. A neural-network-based model predictive control of three-phase inverter with an output LC filter. IEEE Access 2019, 7, 124737-124749. [CrossRef]

21. Gardezi, M.S.M.; Hasan, A. Machine learning based adaptive prediction horizon in finite control set model predictive control. IEEE Access 2018, 6, 32392-32400. [CrossRef]

22. Dragičević, T.; Novak, M. Weighting factor design in model predictive control of power electronic converters: An artificial neural network approach. IEEE Trans. Ind. Electron. 2018, 66, 8870-8880. [CrossRef]

23. Mohamed-Seghir, M.; Krama, A.; Refaat, S.S.; Trabelsi, M.; Abu-Rub, H. Artificial Intelligence-Based Weighting Factor Autotuning for Model Predictive Control of Grid-Tied Packed U-Cell Inverter. Energies 2020, 13, 3107. [CrossRef]

24. Carlet, P.G.; Tinazzi, F.; Bolognani, S.; Zigliotto, M. An effective model-free predictive current control for synchronous reluctance motor drives. IEEE Trans. Ind. Appl. 2019, 55, 3781-3790. [CrossRef]

25. Lin, C.K.; Liu, T.H.; Fu, L.C.; Hsiao, C.F. Model-free predictive current control for interior permanent-magnet synchronous motor drives based on current difference detection technique. IEEE Trans. Ind. Electron. 2013, 61, 667-681. [CrossRef]

26. Lin, C.K.; Lai, Y.S.; Yu, H.C. Improved model-free predictive current control for synchronous reluctance motor drives. IEEE Trans. Ind. Electron. 2016, 63, 3942-3953. [CrossRef]

27. Khalilzadeh, M.; Vaez-Zadeh, S.; Eslahi, M.S. Parameter-free predictive control of IPM motor drives with direct selection of optimum inverter voltage vectors. IEEE J. Emerg. Sel. Top. Power Electron. 2019, 9, 327-334. [CrossRef]

28. Rodriguez, J.; Heydari, R.; Rafiee, Z.; Young, H.A.; Flores-Bahamonde, F.; Shahparasti, M. Model-Free Predictive Current Control of a Voltage Source Inverter. IEEE Access 2020, 8, 211104-211114. [CrossRef]

29. Heydari, R.; Young, H.; Rafiee, Z.; Flores-Bahamonde, F.; Savaghebi, M.; Rodriguez, J. Model-Free Predictive Current Control of a Voltage Source Inverter based on Identification Algorithm. In Proceedings of the IECON 2020 The 46th Annual Conference of the IEEE Industrial Electronics Society, Singapore, 18-21 October 2020; pp. 1-6.

30. Amoura, K.; Wira, P.; Djennoune, S. A State-space Neural Network for Modeling Dynamical Nonlinear Systems. In Proceedings of the IJCCI (NCTA), International Conference on Neural Computation Theory and Applications, Paris, France, 24-26 October 2011; pp. 369-376.

31. Song, Y.; Chen, Z.; Yuan, Z. New chaotic PSO-based neural network predictive control for nonlinear process. IEEE Trans. Neural Netw. 2007, 18, 595-601. [CrossRef] [PubMed] 
32. Moumouh, H.; Langlois, N.; Haddad, M. A Novel Tuning approach for MPC parameters based on Artificial Neural Network. In Proceedings of the 2019 IEEE 15th International Conference on Control and Automation (ICCA), Edinburgh, UK, 16-19 July 2019; pp. $1638-1643$.

33. Shi, H.; Wen, H.; Chen, J.; Hu, Y.; Jiang, L.; Chen, G. Minimum-reactive-power scheme of dual-active-bridge DC-DC converter with three-level modulated phase-shift control. IEEE Trans. Ind. Appl. 2017, 53, 5573-5586. [CrossRef]

34. Chiasson, J.N.; Tolbert, L.M.; McKenzie, K.J.; Du, Z. A unified approach to solving the harmonic elimination equations in multilevel converters. IEEE Trans. Power Electron. 2004, 19, 478-490. [CrossRef]

35. Meng, L.; Dragicevic, T.; Vasquez, J.C.; Guerrero, J.M. Tertiary and secondary control levels for efficiency optimization and system damping in droop controlled DC-DC converters. IEEE Trans. Smart Grid 2015, 6, 2615-2626. [CrossRef]

36. Shi, H.; Wen, H.; Hu, Y.; Jiang, L. Reactive power minimization in bidirectional DC-DC converters using a unified-phasor-based particle swarm optimization. IEEE Trans. Power Electron. 2018, 33, 10990-11006. [CrossRef]

37. Sabzevari, S.; Karimpour, A.; Monfared, M.; Naghibi Sistani, M.B. MPPT control of wind turbines by direct adaptive fuzzy-PI controller and using ANN-PSO wind speed estimator. J. Renew. Sustain. Energy 2017, 9, 013302. [CrossRef]

38. Heydari, R.; Khayat, Y.; Naderi, M.; Anvari-Moghaddam, A.; Dragicevic, T.; Blaabjerg, F. A decentralized adaptive control method for frequency regulation and power sharing in autonomous microgrids. In Proceedings of the 2019 IEEE 28th International Symposium on Industrial Electronics (ISIE), Vancouver, BC, Canada, 12-14 June 2019; pp. 2427-2432.

39. Cortes, P.; Rodriguez, J.; Quevedo, D.E.; Silva, C. Predictive Current Control Strategy With Imposed Load Current Spectrum. IEEE Trans. Power Electron. 2008, 23, 612-618. [CrossRef]

40. Lin, X.; Xi, W.; Dai, J.; Wang, C.; Wang, Y. Prediction of Slag Characteristics Based on Artificial Neural Network for Molten Gasification of Hazardous Wastes. Energies 2020, 13, 5115. [CrossRef] 